\title{
Autotraducción y asimetría en el mundo de habla hispana: una perspectiva transatlántica
}

\author{
Rainier Grutman \\ rgrutman@uottawa.ca \\ https://orcid.org/0000-0002-5947-5751 \\ Universidad de Ottawa, Canadá
}

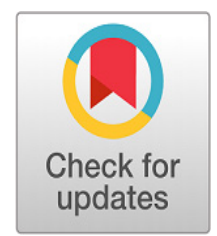

Título de la obra: Literary self-translation in Hispanophone contexts. Europe and the Americas Editoras: Lila Bujaldón de Esteves, Belén Bistué, Melisa Stocco

Editorial: Palgrave Macmillan

Serie: Translation History

Año de publicación: 2019

Número de páginas: 392

ISBN: 978-3030236243

DOI: $10.1007 / 978-3-030-23625-0 \_1$

\section{Dominación y declive}

El presente libro abre nuevos caminos para el estudio de la autotraducción en español. Por su importancia para la valoración transatlántica de la práctica y la política de la autotraducción, invita a hacer una reflexión más general. En lo que sigue, se usará a la vez como barómetro y como trampolín. ${ }^{1}$

Los ensayos sobre Hispanoamérica, en particular, "corrigen el enfoque eurocéntrico actual" (correct the current Eurocentric focus), como lo destaca Anthony Cordingley en la nota publicitaria que figura en la contraportada. Lxs escritorxs estudiadxs provienen de las tres Américas: la del Sur (Chile, Argentina, Perú, Paraguay), como la Central (Guatemala) y la del Norte (México). Tal propuesta de una perspectiva

1 Para distinguir las citas tomadas de este volumen y las que provienen de otras fuentes, las primeras aparecen con el número de la(s) página(s) pero sin fecha o la mención "p.", mientras que las segundas van precedidas del nombre de su(s) autor(es), de la fecha y de la mención "p." (con la paginación). Me complace agradecer a María Laura Spoturno por sus comentarios y sugerencias, que sin la menor duda permitieron mejorar este texto (de cuyos errores - tanto de forma como de contenido — sobra decir que soy el único responsable). 
verdaderamente panamericana complementa muy bien los trabajos, ya numerosos, sobre lxs escritorxs bilingües (de ascendencia chicana $u$ otra) que alternan (y a veces oscilan) entre el español y el inglés en los Estados Unidos.

Para tratar de la autotraducción en España, las editoras del volumen, Lila Bujaldón de Esteves, Belén Bistué y Melisa Stocco, consiguieron la colaboración de investigadorxs reconocidxs provenientes de las principales minorías lingüísticas: Elizabete Manterola Agirrezabalaga y Garazi Arrula Ruiz (País Vasco), Josep Miquel Ramis (Cataluña) y Xosé Manuel Dasilva (Galicia). Cabe subrayar que España se caracteriza por una verdadera proliferación de autotraducciones. Más de doscientxs escritorxs tradujeron al menos una vez obra propia a lo largo del transcurso del último siglo según Julio César Santoyo (2015), cuyas indagaciones arqueológicas deberían ser de lectura obligada para cualquier persona interesada en el tema.

El conjunto de trabajos aquí recogidos muestran de manera clara y elocuente la asimetría inherente a la mayoría de autotraducciones que tienen que ver con el español. Sin embargo, si bien documentan de manera directa la dominación del español como idioma global, también ilustran su declive, aunque de manera indirecta y quizás involuntaria.

La primera de estas dos dimensiones conciernela dominación del castellano. En los extensos territorios americanos que quedaron bajo el dominio de la Corona española después del Tratado de Tordesillas, la hegemonía de "la lengua, compañera del imperio" se mantiene indisputada en términos generales, a pesar de la reciente revalorización de las lenguas originarias, sobre todo a partir de las conmemoraciones de 1992. En estas mismas fechas, las minorías lingüísticas de la Península Ibérica habían abogado con éxito por obtener un estatus "cooficial" en sus regiones respectivas del Estado español. Fue una manera de compensar por décadas de monolingüismo, planificado e implantado con particular brutalidad por el régimen franquista, pero cuyas raíces ideológicas pueden remontarse a los Austrias (fue Felipe v quien promulgó los Decretos de Nueva Planta). A pesar de muchos avances hacia la "normalización lingüística" (como se llama en catalán el uso público de pleno derecho desde Lluis Aracil (1982 [1965]), el balance aún está lejos de inclinarse a favor de las lenguas minoritarias de España.

En ambos contextos, el panamericano como el peninsular, es notable que la autotraducción ganó popularidad como práctica en períodos de "transición democrática", en los que se abrió el abanico de lenguas admitidas en el espacio público. El acceso a y la educación en los idiomas nativos de las minorías respectivas son condiciones mínimas para producir ciudadanxs bilingües alfabetizadxs en dos lenguas, lo que, a su vez, permite participar en diferentes formas de escritura bilingüe, entre las cuales se puede ubicar la autotraducción.

También hay señales de declive del español, sin embargo. Aunque todos los ensayos confirman su fortaleza actual, tanto en España como en Hispanoamérica, el propio volumen -en su presentación y su distribución - indica que, al menos en el ámbito cientifico, la posición dominante del español parece mucho menos asegurada. Volveremos sobre esta paradoja al final, después de analizar en mayor detalle las principales tendencias (pero también los casos excepcionales) de la "autotraducción literaria en contextos de habla hispana".

\section{Tres casos idiosincráticos}

Empezaré por tres casos idiosincráticos, excepcionales con respecto a las trayectorias habituales de la mayoría de escritorxs cuyas lenguas incluyen al español (y que, por lo tanto, se podrían llamar hispanógrafxs).

\subsection{Vicente Huidobro}

El poeta creacionista Vicente Huidobro pasó varios años en París antes de regresar a su Chile natal en 1932. Por lo tanto, su práctica 
como escritor y autotraductor se puede calificar de transatlántica. Huidobro no operaba entre dos literaturas en contacto: eligió el francés como antídoto contra el estilo español, que consideraba demasiado barroco, según un proceso descrito con maestría en este volumen por Marcos Eymar. ${ }^{1}$ Lo que caracteriza el trabajo translingüe de Huidobro es pues la distancia geográfica. Su travesía metafórica y abstracta de y entre lenguas estaba apuntalada por una travesía concreta del Océano Atlántico. Era un "autotraductor migratorio" más bien que "sedentario", para retomar una distinción hecha en otro lugar (Grutman 2015, pp. 10-11). Por seguir con la metáfora ornitológica, podría decirse que sus vaivenes transatlánticos (porque hubo más de un viaje de ida y vuelta) recuerdan la trayectoria de las llamadas "golondrinas", es decir, los obreros agrícolas — sobre todo italianos - que participaban cada año en la cosecha en Argentina y luego volvían a sus tierras de origen. ${ }^{2}$ Tampoco tenían motivos políticos sus viajes, a diferencia de lo que sucedió con Agustí Bartra i Lleonart, otro autotraductor migrante estudiado en estas páginas.

\subsection{Agustí Bartra y el exilio catalán}

Durante las tres décadas que duró su exilio mexicano, Bartra nunca dejó de escribir en catalán, aunque en varias ocasiones preparó él mismo una versión equivalente en castellano. Paula Simón se concentra en uno de estos casos:

1 En su libro sobre autores hispanoamericanos translingües, Eymar dedicó ya varias páginas a Huidobro (Eymar, 2011, pp. 290-298; véase asimismo Canonica, 1993).

2 "En el periodo 1871-1900 llegaron a la Argentina 2700000 inmigrantes, de los cuales se radicaron 1700000 , pues muchos de ellos eran los denominados golondrinas, que luego de levantar las cosechas, regresaban a sus lugares de origen, convertidos en obreros temporarios. En el periodo 1900-1914 llegaron otros 3100000 , de los que se radicaron, por la misma causa, sólo la mitad” (Sáez Capel, 2001). la novela Xabola, que tuvo tres avatares, el resultado de dos reencarnaciones. Primero se publicó en catalán en México, luego Bartra la tradujo al castellano y más tarde todavía la "retro(auto)tradujo" al catalán, en vísperas de su regreso a España.

El examen que propone Simón de esta "doble autotraducción" complementa el trabajo de Lucía Azpeitia Ortiz (2017) y llama nuestra atención sobre el exilio republicano en México. Si bien es cierto que ha recibido atención crítica (Bernecker, 2011), el tema merece ser examinado de nuevo en términos de traducción, aunque solo fuera para observar la dinámica multilingüe creada por el componente catalán. Valdría la pena, asimismo, explorar el papel que pudo jugar México como centro intelectual y lugar de publicación paralelo para la escritura catalana diaspórica en la época de Franco. La existencia de publicaciones catalanas en México supone una red de "agentes" y varios intelectuales catalanes contribuyeron a modelar el "campo" literario mexicano. Muchos de ellos fueron también activos como traductores. Es el caso del mismo Bartra, que tradujo del inglés y del francés un número impresionante de obras extranjeras prohibidas por la censura franquista. Estas traducciones circulaban tanto en el mexicano como en otros mercados. ${ }^{3}$

3 La lista completa se encuentra en: https://www. escriptors.cat/autors/bartraa/obra. Bartra tradujo del inglés y del francés, pero ocurrió lo mismo con obras en alemán entre otras manos catalanas. La "Trilogía de Dánzig" (El tambor de hojalata, El gato y el ratón y Años de perro) de Günter Grass, por ejemplo, existe en español gracias a Carles Gerhard, un catalán de origen suizo, muerto en México. En los años 1950 y 1960, Gerhard preparó cantidad de traducciones para Joaquín Mortiz y el Fondo de Cultura Económica (Sáenz, 2018). Otro exiliado catalán, Josep Maria Francès, tradujo El pequeño príncipe (y no todavía El principito) para la editorial Diana. Siempre en México, el barcelonés Felipe Teixidor Benach contribuyó varias traducciones a Sepan Cuántos, la emblemática colección de bolsillo de Porrúa (Atalá, 2020). Etcétera. 


\subsection{Sor Juana Inés de la Cruz}

Otro caso atípico es sor Juana Inés de la Cruz. A diferencia de Huidobro, se destaca por razones ya no de geografía, sino de cronología, ya que pertenece al siglo XVII. Juana Ramírez de Asbaje nació en la entonces denominada "Nueva España", hija de un capitán español y de una madre criolla, es decir, según el sentido antiguo de la palabra, una "europea nacida en las colonias" (Noll, 2004). La estudia aquí Belén Bistué, una especialista del Renacimiento europeo, cuya tesis doctoral examinó las traducciones colaborativas en esta época. $\mathrm{Su}$ capítulo se centra en un texto polifónico y trilingüe (español, latín y náhuatl), compuesto por la poeta mexicana en 1676, con motivo de la fiesta de la Asunción. En el poema final del conjunto estudiado, intitulado "Villancico vIII", Bistué sostiene que sor Juana "traslada" a María de dos maneras. Por un lado, aparece con la piel bronceada por el sol en una canción de "negrillos", escrita en un registro del español que pretende "parodia[r] el habla de los esclavos africanos" (157). Sor Juan recupera aquí el topos de "la moza morena" en los cantares tradicionales de la Península Ibérica. Se asocia ante todo con el mundo morisco, pero había también versiones judeoespañolas de "Yo me soy la morenica":

\footnotetext{
Yo soy la estrella del mar

y en my se uino a incarnar

el que vino a reparar

lo que adam perdido ha.

Yo soy la sin espinas rosa

que salomon canta y glosa

Nigra sum sed formosa

y por my se cantara ${ }^{4}$
}

No sabemos si sor Juana de la Cruz conocía esta versión "a lo divino" del tema profano del oscurecimiento de la tez. La cita bíblica del Cantar de los cantares no aparece en su texto, que

4 Según el texto del Cancionero de Romances impreso en Amberes en 1550, menos conocido que el Cancionero de Uppsala, impreso en Venecia en 1556 (Cotelo García, 2009, pp. 782-783). contiene, sin embargo, varias alusiones al texto veterotestamentario, sobre todo en la parte compuesta en latín examinada por Bistué (153-155).

Donde la primera traslación mariana tematiza cruces culturales entre las tres religiones de Al-Andaluz, en la segunda, sor Juana utiliza el contacto y conflicto en Nueva España entre conquistadores blancos y conquistadxs indígenas, entre colonizadores y colonizadxs, trátese de "negrxs" arrebatadxs al continente africano o de aztecas subyugadxs en su propia tierra. No parece pura coincidencia que esta parte del poema implique el náhuatl y presente a la Santísima Virgen como una noble dama azteca. Viene nombrada aquí por su nombre náhuatl, Tonantzin o "madre sagrada", usado para varias diosas aztecas, pero que ya se había aplicado a la Virgen de Guadalupe. Sor Juana no solo respalda tal uso, sino que su poema exhibe además una notable abertura lingüística al Nuevo Mundo al incorporar varias estrofas en náhuatl.

Bistué considera estas operaciones "como una serie de autotraducciones figurativas" (151), lo que va más allá de otras investigaciones. Hasta ahora, la única "autotraducción verdadera" (148-151) que se había atribuido a sor Juana es un epigrama bilingüe, escrito primero en latín y luego en español. Desarrolla el tema teológico de la corredención de Eva por María, correspondencia inscrita en el palíndromo Eva/ Ave, que, a su vez, se hace eco de una línea del famoso himno medieval Ave, Maris Stella: "Mutans Evæ nomen" (Hokenson y Munson, 2007, pp. 109-112; Leonetti, 2012).

\section{1992 y el giro indígena en Hispanoamérica}

Julio César Santoyo llama la atención sobre el "resurgimiento de las literaturas en lenguas indígenas americanas" (25). En su texto, muy bien documentado, encontramos a más de cincuenta autorxs que trabajan simultáneamente en español y en una de las numerosas lenguas originarias de las Américas. Por su parte, las 
contribuciones de Melisa Stocco y Eva Gentes se acercan respectivamente a lxs poetas mapuches y a lxs escritorxs mexicanxs. Conviene recordar que tanto Gentes (2016) como Stocco (2018) dedicaron (parte de) su tesis doctoral a la autotraducción indígena. El trabajo de Gentes abarcaba varias lenguas romances (e incluye a autorxs mexicanxs, francesxs y españolxs), mientras que Stocco se centraba en poetas mapuches de Argentina y Chile: Leonel Lienlaf, Elicura Chihuailaf, Rayen Kvyeh, María Teresa Panchillo, Liliana Ancalao y Adriana Paredes Pinda.

Juntos, los artículos de Santoyo, Stocco y Gentes abren un camino completamente nuevo al agregar "zonas de contacto" 5 poco exploradas. Se puede hablar de "zonas" porque las autotraducciones estudiadas en esta colección no ocurren entre países sino dentro de las fronteras de un estado individual. En otras palabras, casi todas son "autotraduccion[es] intraestatal[es] o entre literaturas en contacto" (Ramis, 2013, s. p.). Incluso la escritura mapuche, que tiene una dimensión "interestatal" por haberse desarrollado en ambos lados de la cordillera de los Andes, se encuentra en contacto con los sistemas literarios argentino y (sobre todo) chileno.

Por cierto, hubo estudios aislados en el pasado. Muy relevante para la presente discusión es el trabajo de pionero del chileno Iván $\mathrm{Ca}$ rrasco (1991). Así por ejemplo cuando compara y contrasta el bilingüismo español-francés "cosmopolita" de Vicente Huidobro (que volvemos a encontrar) y la interacción digamos "local" entre el español y el mapudungun en la obra de Sebastián Queupul Quintremil. Pero ha cambiado la perspectiva. Hoy, las "versiones paralelas bilingües" y los "textos de doble

5 Fue la Canadiense Mary Louise Pratt (1991, p. 34) quien introdujo la fórmula "contact zones" para referirse a "espacios sociales donde las culturas se encuentran, chocan y luchan entre sí, a menudo en contextos de relaciones de poder altamente asimétricas, como el colonialismo, la esclavitud o sus secuelas" (traducción mía). registro lingüístico en versiones simultáneas y equivalentes, en lenguas distintas por sus propios autores" de los que hablaba Carrasco (1991, pp. 74-76), se dejan estudiar como autotraducciones.

\subsection{Humberto Ak'Abal}

Hace veinte años, Dante Barrientos Tecún (2002) fue el primero en llamar la atención sobre la actividad autotraductora de otra figura clave: el recientemente fallecido Humberto Ak'Abal. Santoyo lo describe aquí como "uno de los escritores indígenas más premiados y conocidos de toda Hispanoamérica" (39-40) y, de hecho, su obra ha sido traducida al francés, al alemán y al inglés. El autoproclamado "tejedor de palabras" (ajkem tzij) guatemalteco compuso en español y en su k'iché nativo, hablado por aproximadamente un millón de personas. Desde un principio, y sobre todo por falta de personal calificado, Ak'Abal tradujo sus textos k'iché al castellano: "Creo que soy dos poetas en una persona. Primero fue un poco temeroso hacer este arriesgado trabajo, pero a medida que lo he estado ejercitando he adquirido seguridad, y cada vez me siento más bilingüe" (Ak'Abal en Campos, 2013, s.p.).

Tampoco es reciente el descubrimiento del primer poeta mapuche, Leonel Lienlaf. Lo mencionan Santoyo (31) y Stocco (103) - quien ya lo había estudiado previamente (Stocco, 2013, 2018, pp. 92-130) - pero fue en Francia, gracias a Adriana Castillo-Berchenko (2004), que apareció una apreciación muy temprana de su obra.

Vistas sus fechas de publicación (Barrientos Tecún, 2002; Castillo-Berchenko, 2004), no es de extrañar que estas primeras exploraciones carecieran de referencias a los estudios de traducción. Va a cambiar la situación a partir de la investigación doctoral de Hana Muzika Kahn (2007, 2008). Aunque no lo revele el título de su tesis ("Bilanguaging' in the literary works of

6 El término bilanguaging es de Walter Mignolo, cuyos trabajos contraponen el proceso dinámico del 
bilingual Mayan authors"), el marco traductológico fundamenta su análisis. Más importante para nuestro propósito: Kahn compara las versiones gemelas de una serie de textos - firmados por Humberto Ak'abal (k'iché), Gaspar Pedro González (q'anjob'al) y Víctor Montejo (jakaltek) - para ver cómo se manifiesta y se traduce la voz maya en español.

\subsection{La poesía mapuche}

Cuesta imaginar un contraste más grande que el que separa la cultura mapuche, con siglos de tradición, de la escritura mapuche, conocida en las últimas décadas. La razón radica en las políticas, coloniales antes de ser nacionales, de discriminación y desplazamiento sistémicos, tanto en Argentina como en Chile, que llevaron al mapudungun a ser marginado y reprimido. Para Stocco (105-107), la autotraducción participa de un "bilingüismo post-interdicción" más largo; es una manera de reclamar -a veces incluso recuperar- "el idioma silenciado", como lo llama Liliana Ancalao (106). De hecho, ni ella ni Elicura Chihuailaf crecieron hablando su lengua ancestral, sino que son lo que en inglés suele llamarse "heritage language learners" (Fishman, 2001). Al igual que un gran número de mapuches, tuvieron que aprender el mapudungun (Zúñiga, 2007; Zúñiga \& Olate, 2007). Teniendo en cuenta estos niveles de dominio muy variables, no sorprende que lxs poetas mapuches estudiadxs por Stocco suelan escribir en español y traducirse posteriormente a una lengua ancestral con la que se identifican más, pero que no deja de ser su segunda lengua (L2). No pocas veces colaboran con personas que disponen del mapudungun como primera lengua (L1) y son, por ende, más versadas en

bilenguaje al estado del "bilingüismo convencional donde ambos idiomas se mantienen en su pureza pero al mismo tiempo en su asimetría" (Mignolo, 2000, p. 231). El bilenguaje, tal y como lo encuentra Mignolo en Arguedas, Anzaldúa o el discurso zapatista, "no es una preocupación gramatical sino política" enfocada a "reparar la asimetría de las lenguas y denunciar la colonialidad del poder y del saber." (Mignolo, 2000, pp. 252-253, traducción mía) el idioma. En términos de "direccionalidad", se trata de autotraducciones L1>L2 o "inversas", aunque no en el sentido tradicional de "realizada[s] de la lengua materna hacia une lengua extranjera" (De la Cruz Trainor, 2004, p. 54), ya que lxs poetas mapuches en cuestión no consideran el mapudungun como "extranjero", sino como "patrimonial" (y tampoco es cierto que su L1, el español, les parezca "materno", con todo lo que suele asociarse con este adjetivo). ${ }^{7}$

En términos de lo que Abram De Swaan (2001) bautizó la "galaxia" de las lenguas, se observa pues un movimiento "centrífugo", desde el sol hacia sus planetas periféricos. Otra metáfora que expresa la misma idea es la del río. Al igual que una corriente de agua, la llamada "infra-autotraducción" (Grutman, 2011, pp. 81-82) parte de las alturas y va hasta el nivel del mar, es decir, va "río abajo", de un idioma de mucho prestigio geopolítico a otro que tiene mucho menos "capital simbólico." En el caso que nos ocupa, el movimiento vertical arriba-abajo parte del español, cuyo peso específico es mucho más elevado que el mapudungun, minorizado y marginado.

\subsection{Hacia una revitalización lingüística en Abya Yala}

Dicho esto, se detectan señales de cambio desde la década de los 80, caracterizada por una gradual transición a la democracia en varios países sudamericanos. Nótese por ejemplo que Se ha despertado el ave de mi corazón (Nepey ñi günün piuke), libro bilingüe de Leonel

7 Ocurre algo parecido en Colombia con Fredy Chikangana (cuyo nombre quechua, Wiñay Mallki, significa "raíz que permanece en el tiempo"). Sus poemas (tikana) aparecen en ambas lenguas, pero el proceso creativo se inicia en español, lengua vehicular en su comunidad de habla. Solo después convierte sus tikana en quechua culto, herramienta literaria aprendida lejos de sus tierras, en los Andes centrales. O sea que la (auto)traducción es la versión quechua, no al revés (Brígido-Corachán y Domínguez, 2019, p. 85). 
Lienlaf, que se suele considerar como el acto de bautizo de la escritura mapuche, sale en los últimos años de la dictadura de Augusto Pinochet. En la misma década, otro general, Alfredo Stroessner, pierde el control del poder en Paraguay. El guaraní se había convertido en un símbolo nacional de orgullo durante la guerra del Chaco ${ }^{8}$ (1932-1935) y alcanzó un nivel "conacional" bajo Stroessner, en 1967. Sin embargo, esta lengua, a la vez simbólicamente valorizada por el pueblo (es un pilar de su identidad) y concretamente menospreciada por las élites postindependencia, tuvo que esperar hasta la Constitución democrática de 1992 para adquirir un estatus plenamente oficial, a pesar de ser el habla nativa de más de la mitad de la población. Desde entonces, se trata de integrar el guaraní en la enseñanza gracias al Plan de Nacional de Educación Bilingüe de Mantenimiento (Choi, 2005, pp. 236-237; Rubin, 1962 y 1974; Corvalán, 1981).

Otro factor importante para el desarrollo de tales políticas lingüísticas fue el $\mathrm{v}$ centenario del desembarco de Colón en tierras que el navegante genovés suponía "indias". Las ceremonias conmemorativas del "descubrimiento" condujeron a un examen de conciencia $\mathrm{y}$ constituyeron un hito en un proceso lento pero constante de revitalización lingüística. Es en este contexto que se propuso la voz "Abya Yala" " "tierra madura" en lengua guna de $\mathrm{Pa}$ namá, en oposición a "Nuevo Mundo", voz atribuida a los europeos) como alternativa de la etiqueta eurocéntrica derivada del nombre de pila del florentino naturalizado castellano Amerigo Vespucci.

En 1993 vieron la luz, por ejemplo, la Asociación Mexicana de Escritores en Lenguas Indígenas

8 Eso es cuando Narciso Ramón Colmán ("Rosicrán") publicó Ñande îpî cuéra [Nuestros antepasados]: poema etnogenético y mitológico escrito en guaraní y autotraducido al español. Se puede consultar aquí: http://portalguarani.com/376_narciso_ramon_ colman_rosicran_/9733_nande_300p_300_cuera_nuestros_antepasados_por_narciso_r_colman_rosicran_.html
(ELIAC) y el premio Nezahualcóyotl de Literatura en Lenguas Indígenas. Desde entonces, este galardón ha ganado cada vez mayor prestigio y reconocimiento como distinción literaria. En la actualidad, señala Gentes (8283, 93-94), se considera como una referencia para la elección de textos fuente en el mundo editorial de habla inglesa o francesa. Más de sesenta "lenguas originarias" de México —lo que corresponde al quince por ciento de la población ${ }^{9}$ - recibieron algún tipo de reconocimiento oficial una década más tarde, en 2003, que es también el año en que el vecino país de Guatemala aprobó su propia Ley de Idiomas Nacionales. Es decir, un giro decisivo se evidencia a partir de 1992, fecha que, mucho más que una conmemoración retrospectiva, se reveló como una proyección hacia el futuro.

Aún así, quedan muchos escollos, tanto en términos de ingeniería lingüística (codificación y estandarización de los idiomas) como de visibilidad en la esfera pública. En su tesis, Gentes (2016, p. 93) enumeraba a no menos de quince autotraductorxs indígenas de México, pero se centraba en Natalia Toledo Paz (Gentes, 2016, pp. 357-369). En el presente libro, Gentes examina otra vez a Toledo, en conjunción con la poeta zapoteca Irma Pineda Santiago y la poeta maya yucateca Briceida Cuevas Cob. Para las tres, como para la mayoría de lxs veinte y tantxs escritorxs, cuyas experiencias se reflejan en la contribución de Gentes, "la autotraducción es la regla" (87). Es cierto que los subsidios estatales, los premios literarios y las clases de alfabetización fomentan la escritura en lenguas indígenas y crean nuevas oportunidades. Se comprueba, no obstante, que las tres escritoras estudiadas opinan

9 “Según la Encuesta Intercensal 2015, nuestro país cuenta con 7 millones 382 mil 785 hablantes de alguna lengua indígena. [...] En México existen actualmente 364 variantes lingüísticas, las cuales son habladas por 68 grupos indígenas y provienen de 11 familias lingüísticas distintas". (https://constitucionenlenguas.inali.gob.mx/lenguas-originarias 
no tener más remedio que traducir su obra en español si quieren llamar la atención.

Aquí también, como en el contexto mapuche, las autotraducciones son "inversas" porque parten del idioma natal (L1). Consideradas desde el punto de visto galáctico apuntado más arriba, sin embargo, funcionan de manera opuesta. Esta vez, la L1 de partida no es el español de los colonizadores de antaño, sino el idioma indígena colonizado y de menor prestigio. El español, en cambio, se convierte en lengua meta, lengua de promoción nacional e internacional. Es decir, domina en el ámbito mexicano la traducción "río arriba", la "supra-autotraducción" (Grutman, 2011, pp. 81-82). Y no solo en México: Santoyo ve tal tipo de autotraducción como "una clara constante de la literatura indígena hispanoamericana" (34), visto que "todos estos textos bilingües, sean mapuches, mayas, zapotecas, guaraníes o quechuas, [son] traducidos en general por el propio autor desde la lengua indígena al español" (44).

Tal como ocurre en otros contextos minoritarios, las autotraducciones acaban, pues, siendo un arma de doble filo (Grutman, 2009, p. 131). Hay quien se preocupa por el destino de las lenguas minorizadas y del peligro que corren de desaparecer detrás (o debajo) de versiones autorales en español, pero la mayoría se resigna delante de una realidad juzgada inevitable. El trabajo de Gentes deja constancia de esta resignación entre 1xs autorxs indígenas de México, pero existen otras actitudes. Humberto Ak'Abal, por ejemplo, era más bien favorable a la autotraducción como forma de promoción. Según declaraba hace casi treinta años: "Mi poesía la pienso en mi lengua materna, el idioma K'iché; luego la traduzco al español para universalizarla" (Ak'Abal, citado en Barrientos Tecún, 2002, s. p.). Reiteró su posición en una entrevista reciente: "Como no tenemos traductores en nuestras lenguas mayas, la autotraducción es una necesidad para universalizar el pensamiento" (Cruz, 2014, s. p.). Para él, se trataba al mismo tiempo de una "necesidad" y de una suerte de oportunidad. Se habrá advertido que el poeta guatemalteco enfoca al problema a través de una lente "universalista" y usa un tipo de discurso reminiscente de la Ilustración y del Romanticismo. Si las hiciera una persona no indígena, afirmaciones como estas podrían resultar sumamente problemáticas en la medida en que se trata de construcciones discursivas, no de realidades históricas $u$ ontológicas. Deja entrever la postura de Ak'Abal, sin embargo, el poder (o al menos el potencial) de promoción que tiene el hecho de firmar la propia obra en traducción: se trata de un gesto no solo poético sino también político.

\section{La resistencia de las minorías lingüísticas de España}

De ahí que al otro lado del océano Atlántico, se estén alzando voces cada vez más críticas con respecto a las "oportunidades" que brinda la supra-autotraducción. En un ensayo reciente, Josep Ramis llegó incluso a hablar del "fracaso de la autotraducción en la literatura catalana" (2017, p. 100). En los primeros años de la dictadura de Franco, publicar en catalán era casi imposible (excepto desde el extranjero, como vimos con Bartra). Los escritores que no habían dejado España y que buscaban una salida "para sus obras literarias en catalán anteriores a la Guerra [Civil]" recurrieron pues a la autotraducción por razones "pragmáticas" e incluso monetarias (Ramis, 2017, p. 100). Se la consideraba una solución temporal, hasta que el idioma catalán recuperara sus plenas funciones. Pero el régimen franquista duró cuatro décadas. Durante ese extenso período, varias generaciones de niños catalanes se formaron en español, sin aprender a escribir su primera lengua hablada. Así empezó a iniciarse un proceso de la substitución lingüística que casi le ocasionó un quiebre fatal a la expresión literaria en catalán. Ni siquiera las leyes lingüísticas de los años ochenta del siglo pasado, que tanto hicieron para consolidar el 
estatus del catalán en la sociedad, consiguieron cambiar el rumbo. De hecho, desde la muerte de Franco, parece haber más supra-autotraducciones que nunca. Anticipando las observaciones aquí formuladas acerca de la "obligación" de traducirse (Gentes, 88; Arrula-Ruiz y Manterola Agirrezabalaga, 242), Ramis se niega a hablar de una "elección voluntaria" (2017, p. 103), sino que la ve como una condición "impuesta" a lxs escritorxs catalanxs por los editores.

\subsection{El País Vasco}

Hacen eco a tal visión en este volumen lxs escritorxs que "renuncian" a traducir obra propia "en el contexto de las relaciones asimétricas entre el castellano y el euskera" (Arrula-Ruiz y Manterola Agirrezabalaga, 241). Como Ramis, sus colegas vascas constatan que la supraautotraducción desde el euskera "ha ido aumentando de manera continuada desde la década de los 80" (245). A pesar de extensas investigaciones, no dieron con ninguna autotraducción literaria que tuviera "el euskera como lengua meta, sino que siempre ha resultado ser lengua de partida" (245). Confirman también la presión ejercida sobre lxs escritorxs minoritarixs: "se impulsa a los autores vascos a que se encarguen en primera persona del trasvase de su obra al castellano" (245).

No obstante, algunxs resisten, incluso si son bilingües y biculturales. Su rechazo de la autotraducción es una forma de "lealtad lingüística". ${ }^{10}$ Se trata de proteger no solo las lenguas minoritarias, sino también la autonomía de las literaturas que les corresponden. Para Joseba Sarrionandia, "si los escritores vascos tienen siempre al español por intermediario", la supraautotraducción "aumentará la tendencia de la literatura vasca a ser apéndice de la española" (253). Ur Apalategi tampoco quiere sistematizar la práctica, porque "las lenguas se encuentran en una relación de poder" (254).

10 Weinreich (1953, pp. 99-101, 106-108) describió la por él llamada "lealtad lingüística" (language loyalty) como una reacción a las interferencias y a la transferencia lingüística (language shift).

\subsection{Cataluña}

Al parecer, en el País Vasco los términos del contrato autotraductor son más duros aún que en Cataluña. Lo muestra Josep Ramis en su aportación. Empieza por dar el ejemplo de Sebastià Juan Arbó, que se autotradujo de manera "continua bidireccional" (357) entre su catalán materno y el castellano oficial del Estado franquista, con el vertiginoso resultado de que algunos de sus títulos están disponibles en seis, siete o incluso diez ediciones diferentes. Para Arbó, como para Bartra (328-329), la costumbre de traducirse acabó por integrarse plenamente en el proceso de (re)escritura.

Inspirándose de Gentes (2016, pp. 522-563), Ramis también señala autotraducciones multidireccionales. Varixs catalanxs expatriadxs optaron por agregar una tercera lengua a su repertorio: el francés para Josep Carner y Víctor Mora, y, en fechas más recientes, el inglés para Roser Caminals y Marta Cardona (instaladas en los Estados Unidos y en Inglaterra, respectivamente) o incluso el neerlandés para Laia Fàbregas. Otro perfil todavía ofrece Monika Zgustová, barcelonesa adoptiva nacida y criada en Praga: "Normalmente, escribe primero en checo, su lengua materna, pero después se autotraduce tanto al catalán como al español —a veces, primero a una de estas lenguas $\mathrm{y}$, a veces, primero a la otra" (332). En la Cataluña actual, los dramaturgos ${ }^{11}$ están muy habituados a tales cambios de dirección: aunque "escriben principalmente en catalán [...], cada vez más escriben según los encargos que reciben, ya sea en una lengua $u$ otra, y se autotraducen a su otra lengua de creación" (330).

Domina, sin embargo, el tráfico cuesta arriba, la supra-autotraducción, como en América Latina y en otras partes de España. Es sintomático a tal respecto el bilingüismo asimétrico de Terenci Moix, que "nunca autotradujo ninguna de sus obras escritas originalmente en español hacia el catalán" (337) pero sí proporcionó una versión

11 Véase el sitio web www.catalandrama.cat 
castellana de varios libros suyos escritos en catalán. La única excepción parece ser su primera novela, El dia que va morir Marilyn, en la medida en que la edición original en catalán (de 1969) estaría basada en un manuscrito español inédito, intitulado "El desorden". Posteriormente, Moix ayudó a José Miguel Velloso con su traducción al español, que el propio Moix revisó a fondo en 1984 antes de dedicarse él mismo (en 1996) a una reescritura intralingüística del texto catalán de 1969. Son cinco, pues, las versiones de esta novela (véase Tietz 2002, pp. 85-87 y aquí, 292-293, 337), pero tampoco se pueden descartar posibles relaciones multilaterales: pudo haber más de un texto fuente para las versiones más recientes, por ejemplo.

\subsection{Galicia}

Casi igual de complejo es el caso presentado por Xosé Manuel Dasilva. La novela Nos pagos de Huinca Loo (1982), escrita en gallego por Xavier Alcalá, fue traducida casi en seguida en "un español criollo rioplatense" (293) por Antonio Santamarina, escritor y político gallego residente en Argentina. Se explica tal elección por el hecho que la novela original era ambientada en la localidad argentina de Orense. Sin embargo, Alcalá va a refundir el texto gallego en 1992 y decide trasladarlo él mismo al castellano. En comparación con la novela de Terenci Moix comentada arriba, se advierte pues una diferencia con respecto a la direccionalidad. Mientras que Moix reelaboró primero la traducción española antes de actualizar la correspondiente versión en lengua minoritaria (el catalán, en su caso), Alcalá procedió al revés: reelaboró el texto gallego años antes de traducirlo español.

\section{De los textos a los contextos}

Algunos ensayos examinan las maneras en que las versiones lingüísticas se enriquecen mutuamente. Eva Gentes (90) lo muestra a propósito de las ediciones bilingües de Toledo Paz y Pineda Santiago. Paula Simón (229-234) documenta los cambios estilísticos realizados por Bartra en las distintas versiones de Xabola. En general, sin embargo, este volumen se centra más en los contextos que en los textos, trata más de la dimensión política del (no) traducirse que del potencial poético de tal operación. Parece lógico el enfoque (anunciado por el título, La autotraducción literaria en contextos de habla hispana), dada la preponderancia de relaciones asimétricas entre el español y las lenguas discutidas. En su mayor parte, estas últimas se pueden calificar de "minoritarias" o "minorizadas", calificaciones no absolutas, sino relativas: cada lengua parece minoritaria (o no) con respecto a otra.

Queda más claro todavía este carácter relativo cuando se adopta una perspectiva global. Existen varias maneras para "medir" el "peso relativo" de las lenguas en la "galaxia" o el "sistema mundial de idiomas" (De Swaan, 2001), pero todas van más allá del mero número de hablantes nativos para incluir varios otros parámetros. En el "Barómetro de las lenguas del mundo"12 de los hermanos Calvet, por ejemplo, intervienen no menos de doce factores. Además de la cifra de hablantes L1, se ha medido la entropía de los idiomas (la distribución geográfica de sus hablantes) y su carácter "vehicular", ${ }^{13}$ el número de países en los que tiene estatus oficial y de universidades donde se usa como lengua de enseñanza, así como la cantidad de libros traducidos (en y de cada lengua) y de premios literarios internacionales, los artículos en Wikipedia y la tasa de penetración de Internet, la tasa de fecundidad y el índice del desarrollo humano (IDH). Para hacer sus cálculos, los hermanos Calvet dieron la misma importancia a cada uno de estos factores.

12 Se puede consultar aquí: http://www.wikilf.culture.fr/barometre2017/index.php. La edición de 2017 incluye 634 idiomas que cuentan con más de 500000 hablantes, según los datos del Texas Summer Institute of Linguistics (www.ethnologue.com), cuyas limitaciones son conocidas y reconocidas por los hermanos Calvet.

13 Según la actualización 2021 del Diccionario de la lengua española (RAE), se considera "vehicular" la lengua "que sirve de comunicación entre grupos de personas de lengua materna distinta". 
El español se sitúa en el tercer lugar, por detrás del inglés y del francés, pero muy por delante del catalán (posición 23) y más aún del gallego y del euskera (posiciones 50 y 52, respectivamente). Cifras como estas pueden interpretarse de dos maneras: o se considera que el vaso está medio vacío o se considera que está medio lleno. Desde el primer punto de vista, cabe recordar la posición poco ventajosa de las lenguas minoritarias de España en la Unión Europea. El irlandés (Gaeilge) es lengua de trabajo en la UE porque tiene estatus oficial en el Estado Libre de Irlanda, mientras que el catalán, el gallego y el euskera, a pesar de ser habla nativa de bastante más personas, siguen siendo invisibles por falta de ser reconocidas por parte del Estado español, donde su estatus cooficial se limita a sus respectivas regiones (o "comunidades autónomas”, según la terminología española).

Mirando las cosas de otra manera (el vaso medio 1leno), prontamente nos damos cuenta de la posición relativamente privilegiada de las lenguas minoritarias de España, ya sea en términos de financiamiento cultural, posibilidades educativas (incluida la educación postsecundaria) o de políticas de alfabetización de manera general. Sus posiciones respectivas en el barómetro de los hermanos Calvet son infinitamente más cómodas que las de cualquiera de las lenguas originarias de las Américas. Para empezar, solo media docena de estas últimas aparecen en la lista de Calvet, que no tiene en cuenta lenguas con menos de medio millón de hablantes nativos. El quechua se sitúa en la posición 143 (es decir, casi cien escalones "por debajo" del euskera), seguido de cerca por el aymara (146) y el guaraní (147). Bastante más lejos se encuentran el mapudungun (223) de Chile y Argentina, el náhuatl (253) de México y el maya de la península de Yucatán (281), lenguas que por lo tanto pueden ofrecer poca resistencia a la "fuerza centrípeta" del español.

La siguiente evaluación de la situación en Guatemala permite hacerse una idea del tipo de desequilibrio que esto conlleva:
Todos los poetas contemporáneos publican en español guatemalteco y se han autotraducido hacia o desde sus respectivos idiomas mayas. No hay ningún poemario que se haya publicado en lengua maya únicamente; muchos se publicaron en español pero la mayoría de las ediciones son bilingües: en ellas los textos originales y traducidos se enfrentan como en un espejo, tanto literal como figurativamente. Se han traducido varios textos literarios mayas a otros idiomas, sobre todo en idiomas del mundo occidental, pero siempre a partir de su versión española. (mi traducción de Yanes, 2014, p. 34)

Estas observaciones hacen resaltar dos elementos: el fenómeno de las traducciones indirectas y la preponderancia de las ediciones bilingües, no solo en Guatemala, sino en toda Abya Yala. La práctica la explica Gentes por razones de mercado: "las librerías suelen ser reacias a almacenar obras en idiomas indígenas" (85), mientras que las ediciones bilingües no excluyen al lectorado hispanohablante. Otro factor, prosigue Gentes, es el hecho que muchxs lectorxs potenciales se escolarizaron en español y "no puede[n] leer textos en su lengua materna" (86). Imperfectas como son, tales ediciones al menos permiten "visibilizar" la lengua originaria (p. 87). Tanto Gentes (94-95) como Santoyo (44-45) dejan constancia de tal esfuerzo por parte de lxs traductorxs anglófonxs de esas ediciones bilingües. Susan Smith Nash, Claire Sullivan, David Shook, Sean Sell y Paul Worley, aun si trabajan habitualmente a partir de la (auto)traducción española, evitan "silenciar" al sujeto subalterno colonial. Preocupadxs por no ocultar o borrar la versión original en lengua originaria, se esfuerzan por hacer entender esta última en sus propias traducciones. A fin de lograrlo, muchas veces hace falta trabajar con los autores para adquirir algunos conocimientos, por rudimentarios que sean, de la lengua indígena y llegar a una traducción menos "domesticadora", según la terminología popularizada por Venuti (1995, pp. 17-21), pero que remite a Schleiermacher a través de George Steiner y Antoine Berman. 


\section{El español como lengua intermedia}

Tanto las ediciones bilingües como las traducciones destinadas a mercados y públicos extranjeros, dan una buena medida del peso a la vez importante y limitado del español. Por un lado, el español juega un papel fundamental como relé o "lengua pivote" hacia el francés y sobre todo el inglés. Si bien se hacen traducciones de obras indígenas en Francia, el inglés domina como lengua meta. No son pocxs 1xs escritor$\mathrm{xs}$ indígenas que deben su fama internacional a traducciones publicadas en revistas y antologías estadounidenses (Gentes, 92-93), quizás más todavía que a sus propias autotraducciones, aunque sin estas, aquellas no hubieran visto la luz. Ilustra bien esta situación paradójica el carácter dinámico e inestable, fluctuante, de etiquetas como "minoritario/mayoritario" o "dominado/dominante".

Situar el estatus "minoritario" en una escala móvil, tal y como acabamos de hacerlo, es solo parte de la reflexión. El estatus "mayoritario" es igual de relativo; también conviene matizarlo. Ninguna lengua puede pretender ejercer una hegemonía absoluta, aunque el inglés se acerque peligrosamente de tal estatus hoy. En palabras de Rainer Enrique Hamel:
Se trata del primer caso en la historia de la humanidad en que una lengua se extiende de manera tan masiva, en profundidad y extensión, de modo que adquiere una posición casi monopólica en una serie de campos y amenaza los espacios de muchas otras lenguas. Ni el latín, ni el francés, ni el español ni tampoco el inglés mismo ocuparon jamás en el pasado una posición semejante (2017, p. 43).

A los 300 millones de anglohablantes se suman otros 700 millones de personas que usan el inglés como segunda lengua (Heilbron, 1999, pp. 433-434). Es decir, el inglés debe su posición privilegiada a su condición global de primera L2 en las clases medias de un número creciente de países. Aparece como la reina en el ajedrez: en comparación con el inglés, todos los demás idiomas acaban teniendo menos poder de atracción. Esto incluye al español. La tercera lengua del mundo (según los cálculos de Calvet) "también sufre una reducción de sus espacios como lengua especializada" (Hamel, 2017, p. 50).

Lo ilustra involuntariamente el presente volumen (Figura 1), en cuya portada y contraportada ni siquiera aparece otra lengua que el inglés. Su título bilingüe completo solo aparece en el interior del libro; en la tienda, por así decirlo, pero no en el escaparate. Considerando la dinámica asimé-

Figura 1. Portada y contraportada de Literary Self-Translation in Hispanophone Contexts.

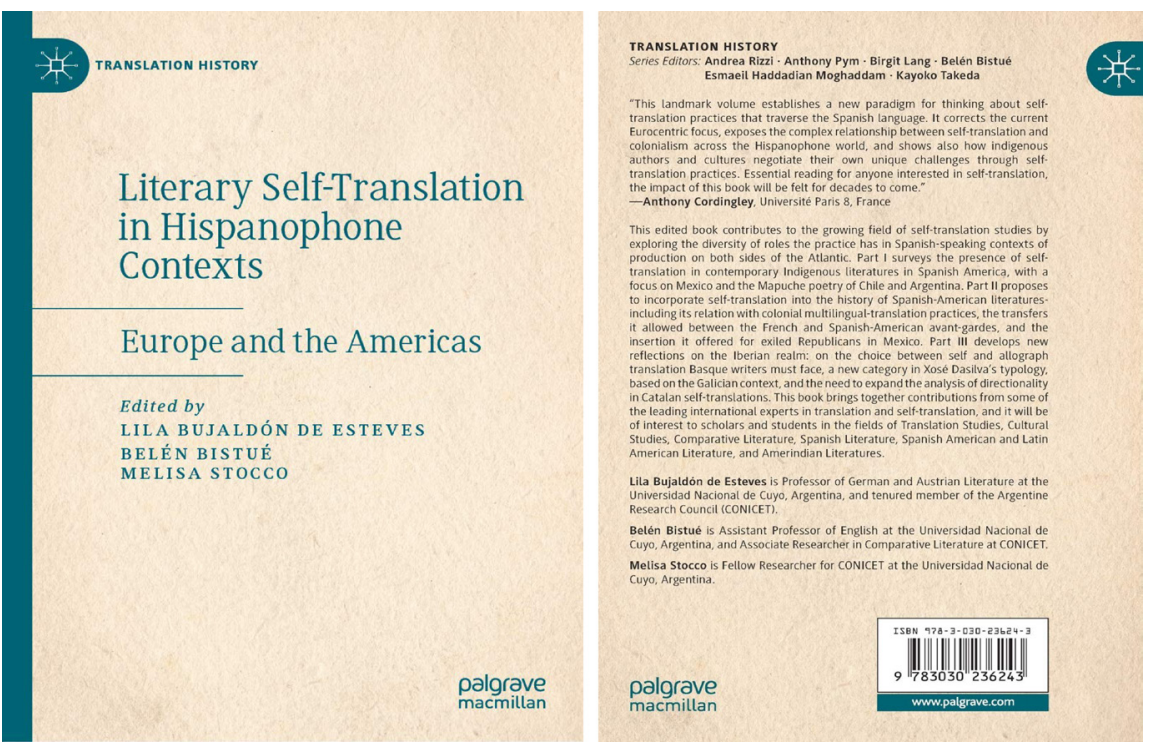


trica descrita anteriormente, no es de extrañar que las lenguas minoritarias (tanto de España como de las Américas) se encuentren más lejos todavía, en el fondo del almacén. Aquellas lenguas no constituyen el cuerpo principal de ningún artículo; su presencia se limita a nombres propios, títulos de libros y algunas citas. Comparemos por ejemplo las dos versiones del ensayo firmado por Garazi Arrula-Ruiz y Elizabete Manterola Agirrezabalaga: las citas en euskera que comporta el texto original (251256) han desaparecido de los pasajes correspondientes (278-281) en la traducción inglesa. Porque cabe señalar que todos los textos redactados en español (la introducción general y seis contribuciones) tienen aquí su equivalente en inglés, mientras que - hecho bastante curioso- los tres ensayos escritos en inglés quedan sin traducir. Por consecuencia de esta asimetría, el conjunto del libro postula a unx lectorx implícitx que lea el inglés pero pueda pasar del español... un perfil que no debe corresponder a muchxs lectorxs empíricxs de Abya Yala. Aquí es el inglés, y no el español, que funciona como "idioma clave" (etimológicamente, la llave que abre las puertas del texto), de manera que lxs hispanohablantes monolingües se encuentran -irónicamente- en la situación habitual de las minorías lingüísticas.

Es de suponer que tal desequilibrio corresponda a la política editorial de Palgrave Macmillan. Sea como fuere, resulta desconcertante en un libro que tanto hincapié hace en cuestiones de asimetría lingüística. Llama también la atención que ningún colaborador es un native speaker anglófono. Los ensayos que aparecen en inglés son el resultado, sea de escritura translingüe (Bistué, Gentes, Simón), sea de traducción (los ensayos de Arrula Ruiz-Manterola Agirrezabalaga, Dasilva, Eymar, Ramis y Santoyo fueron traducidos por Anne Roberts y Ana Elena Roby) y de autotraducción (Stocco). En cierto modo, entonces, el tema central de este libro se ve reflejado en su formato, que al mismo tiempo ilustra la naturaleza relativa y hasta voluble del poder. Aunque la dinámica sociolingüística siga favoreciendo al español siglos después de que se posara el sol en el imperio de los Austrias, parece gozar de menos favores en la "aldea global" del siglo xxi. ¿Sic transit gloria imperii?

\section{Referencias}

Aracil, L. V. (1982). "Conflicte lingüístic i normalització lingüística a l'Europa nova" [1965], en Papers de sociolingüística (pp. 23-38). La Magrana.

Atalá García, L. (2020). Translations in print and many-headed hydras: A study of rewriting in Sepan Cuàntos (1959-2013). Tesis de doctorado, University of Ottawa, Canadá.

Azpeitia Ortiz, L. (2017). Representacions de l'autotraducció als peritextos bibliogràfics d'Agustí Bartra. En E. Gallén y J. F. Ruiz Casanova (Eds.), Bilingüisme, autotraducció i literatura catalana (pp. 233-251). Punctum.

Barrientos Tecún, D. (2002). Interculturalité et bilinguisme dans la littérature guatémaltèque. Le cas d'Humberto Ak'Abal, un poète Quiché. Cahiers d'études romanes, 7, 49-62. https://doi. org/10.4000/etudesromanes.3126

Bernecker, W. L. (2011). Los estudios sobre el exilio republicano en México. En A. Pagni (Ed.), El exilio republicano español en México y Argentina. Historia cultural, instituciones literarias, medios (pp. 33-58). Vervuert-Iberoamericana.

Brígido-Corachán, A. M. \& Domínguez, C. (2019). Los mundos subalternos de la literatura mundial: hacia una comparación de las literaturas indígenas en Abya Yala/las Américas. En G. Müller \& M. Siskind (Eds.), Latin American Literatures in the World/Literaturas latinoamericanas en el mundo (pp. 76-97). Walter De Gruyter.

Calvet, A. y Calvet, L.-J. (2017). Baromètre Calvet des langues du monde. http://www.wikilf. culture.fr/barometre2017/index.php (última consulta: 21 de abril, 2021).

Campos, V. (2013). Entrevista con Humberto Ak'abal: "Soy dos poetas en una persona". Deutsche Welle. https://www.dw.com/es/humberto-akabal-soy-dos-poetas-en-una-persona/a-16606104 
Canonica, E. (1993). La auto-traducción poética creacionista: el caso de Vicente Huidobro. E. Canonica \& E. Rudin (Eds.), Literatura y bilingüismo: homenaje a Pere Ramirez (pp. 323-342). Reichenberger.

Carrasco, I. (1991). Textos poéticos chilenos de doble registro. Revista Chilena de Literatura, 37, 73-84.

Castillo-Berchenko, A. (2004). L'écho de la voix : l'écriture bilingue de Leonel Lienlaf, poète mapuche du Chili. En C. Lagarde (Ed.), Écrire en situation bilingue, (vol. 1, Communications, pp. 197-208). Presses universitaires de Perpignan. http://books.openedition.org/ pupvd/34109

Choi, J. K. (2005). Bilingualism in Paraguay: Forty years after Rubin's Study. Journal of Multilingual and Multicultural Development, 26(3), 233-248. https://doi.org/10.1080/01434630508668406

Corvalán, G. (1981). Paraguay: nación bilingüe. Centro Paraguayo de Estudios Sociológicos.

Cotelo García, R. (2009). Una aproximación a "Yo me soy la morenica" [Uppsala, XLIv]. En J. Cañas Murillo, F. J. Grande Quejigo, J. Roso Díaz (Eds.), Medievalismo en Extremadura: Estudios sobre literatura y cultura hispánicas de la Edad Media (pp. 781-792). Universidad de Extremadura.

Cruz, F. J. (2014). Ak'abal, Humberto, poeta de dos lenguas y un mundo (entrevista). Palimpsesto, 29. http://franciscojosecruz.blogspot.com/ search/label/DIÁLOGOS\%20CON\%20ESCRITORES

De la Cruz Trainor, M. M. (2004). Traducción inversa: una realidad. trans. Revista de traductología, 8, 53-60. https://doi.org/10.24310/ TRANS.2004.v0i8.2963

De Swaan, A. (2001). Words of the world: The global language system. Polity Press.

Eymar, M. (2011). La langue plurielle : le bilinguisme franco-espagnol dans la littérature hispano-américaine (1890-1950). L'Harmattan.

Fishman, J. A. (2001). Three hundred-plus years of heritage language education in the United States. En J. K. Peyton, D. A. Ranard y S. McGinnis (Ed.), Heritage languages in America:
Preserving a national resource (pp. 81-98). Center for Applied Linguistics \& Delta Systems.

Gentes, E. (2016). (Un-)Sichtbarkeit der literarischen Selbstübersetzung in der romanischsprachigen Gegenwartsliteratur. Eine literatur -und übersetzungs- soziologische Annäherung. Heinrich-Heine-Universität.

Grutman, R. (2009). La autotraducción en la "galaxia" de las lenguas. Quaderns, 16, 123-134.

Grutman, R. (2011). Diglosia y autotraducción "vertical" (en y fuera de España). X. M. Dasilva \& H. Tanqueiro (Eds.), Aproximaciones a la autotraducción (pp. 69-92). Editorial Academia del Hispanismo.

Grutman, R. (2015). Francophonie et autotraduction. Interfrancophonies, 6, 1-17. www.interfrancophonies.org.

Hamel, R. E. (2017). La expansión del imperio del inglés: retos para las lenguas súper-centrales. En R. Bein, J. E. Bonnin, M. di Stefano, D. Lauria, M. C.Pereira (Eds.), Homenaje a Elvira Arnoux. Estudios de análisis del discurso, glotopolitica y pedagogía de la lectura y la escritura (tomo II: Glotopolitica, pp. 41-66). Editorial de la Facultad de Filosofía y Letras, Universidad de Buenos Aires.

Heilbron, J. (1999). Towards a sociology of translation. Book translations as a cultural world-system. European Journal of Social Theory, 2(4), 429-444.

Hokenson, J. W. \& Munson, M. (2007). The bilingual text: History and theory of literary self-translation. St. Jerome.

Kahn, H. M. (2007). Maya identity in the bilingual K'iché-Spanish poetry of Humberto Ak'abal. En A. Medina-Rivera \& D. Orendi (Eds.), Crossing over: redefining the scope of border studies (pp.100-110). Cambridge Scholars Publishing.

Kahn, H. M. (2008). Modern Guatemalan Mayan literature in cultural context: Bilanguaging in the literary works of bilingual Mayan authors. Tesis de doctorado inédita, Rutgers University, New Jersey, EE.UU.

Leonetti, F. (2012). Trivia Diosa y Trino Dios: paganismo y cristianismo en una autotraducción de sor Juana Inés de la Cruz. M. R. Árquez 
(Ed.), Autotraduzione. Teoria ed esempi fra Italia e Spagna (e oltre) (177-197). LED.

Mignolo, W. D. (2000). Local histories/global designs. Coloniality, subaltern knowledges, and border thinking. Princeton University Press [Historias locales/diseños globales: colonialidad, conocimientos subalternos y pensamiento fronterizo]. (Traducción de Juanmari Madariago \& Cristina Vega Solís, en Akal, 2003).

Noll, V. (2004). El origen de esp. criollo, port. Crioulo. En J. Lüdtke y C. Schmitt (Eds.), Estudios sobre la historia del léxico español: enfoques y aplicaciones (pp. 257-264). Vervuert-Iberoamericana.

Pratt, M. L. (1991). Arts of the contact zone. Profession (MLA). 33-40. https://www.jstor.org/stable/25595469

Ramis, J. M. (2013). La autotraducción y el difícil encaje de sistemas literarios en contacto. $E U$ -topias, 5. http://eu-topias.org/fr/la-autotraduccion-y-el-dificil-encaje-de-sistemas-literarios-en-contacto/

Ramis, J. M. (2017). The failure of self-translation in Catalan literature. En O. Castro, S. Mainer \& S. Page (Eds.), Self-translation and power: $\mathrm{Ne}$ gotiating identities in multilingual European contexts (pp. 95-117). Palgrave Macmillan.

Rubin, J. (1962). Bilingualism in Paraguay. Anthropological Linguistics, 4(1), 52-58.

Rubin, J. (1974). Bilingüismo nacional en el Paraguay. Instituto Indigenista Interamericano.

Sáenz, M. (2018). Traductores exiliados. En J. Sevilla Muñoz (Ed.), Enfoques actuales de la traducción. Estudios dedicados a Valentín García Yebra [en línea]. Instituto Cervantes. https://crc. cervantes.es/lengua/yebra/

Sáez Capel, J. (2001). Los migrantes y la discriminación en Argentina. Scripta Nova. Revista electrónica de geografia y ciencias sociales, 94(31). http://www.ub.edu/geocrit/sn-94-31.htm
Santoyo, J.-C. (2015). Consideraciones acerca del estatus actual de la autotraducción en la Península Ibérica. Glottopol, 25, 47-58.

Stocco, M. (2013). La voz del desarraigo colectivo en la propia tierra: El caso de los poetas mapuche Elicura Chihuailaf y Leonel Lienlaf. Boletín de Literatura Comparada, 38, 119-136.

Stocco, M. (2018). La autotraducción como práctica ch'ixi textualizadora de un tercer espacio en la actual literatura originaria latinoamericana: El caso de los poetas Mapuche en Argentina y Chile. Tesis de doctorado. Universidad Nacional de Cuyo (ahora publicada como libro: La autotraducción en la poesía mapuche. Peter Lang, 2021).

Tietz, M. (2002). Terenci Moix: El dia que va morir Marilyn / El día que murió Marilyn. ¿Dos versiones lingüísticas, dos versiones culturales? En P. Arnau i Segarra, P. J. i Tous \& M. Tietz (Ed.), Escribir entre dos lenguas. Escritores catalanes y la elección de la lengua literaria / Escriure entre dues llengües. Escriptors catalans i l'elecció de la llengua literària (pp. 83-100). Reichenberger.

Venuti, L. (1995). The translator's invisibility: A history of translation. Routledge.

Weinreich, U. (1953). Languages in contact: Findings and problems. Publications of the Linguistic Circle.

Yanes, K. (2014). Guatemalan Spanish as act of identity: An analysis of language and minor literature within modern Maya literary production. Tesis de maestría, Graduate Center, City University of New York

Zúñiga, F. (2007). Mapudunguwelaymi am? '¿Acaso ya no hablas mapudungun?' Acerca del estado actual de la lengua mapuche. Estudios Públicos, 105, 1-16.

Zúñiga, F. \& Olate, A. (2017). El estado de la lengua mapuche, diez años después. En I. Aninat, V. Figueroa, R. González (Eds.), El pueblo mapuche en el siglo XXI: propuestas para un nuevo entendimiento entre culturas en Chile (pp. 343-374). Centro de Estudios Públicos.

Cómo citar este artículo: Grutman, R. (2022). Autotraducción y asimetría en el mundo de habla hispana: una perspectiva transavtlántica. Mutatis Mutandis, Revista Latinoamericana de Traducción, 15(1), 212-226. https://doi.org/10.17533/udea.mut.v15n1a12 